Short communication

\title{
A comparison of the levels and particle size distribution of lower chlorinated dioxin/furans (mono- to tri-chlorinated homologues) with those of tetra- to octa-chlorinated homologues in atmospheric samples
}

\author{
Xian Zhang a , Minghui Zheng a, b, *, Guorui Liu ${ }^{\text {a }}$, Qingqing Zhu ${ }^{\text {a }}$, Shujun Dong ${ }^{\mathrm{a}}$, \\ Hongxing Zhang ${ }^{c}$, Xiaoke Wang ${ }^{c}$, Ke Xiao ${ }^{a}$, Lirong Gao ${ }^{a}$, Wenbin Liu ${ }^{a}$ \\ a State Key Laboratory of Environmental Chemistry and Ecotoxicology, Research Center for Eco-Environmental Sciences, Chinese Academy of Sciences, \\ Beijing 100085, China \\ b Institute of Environment and Health, Jianghan University, Wuhan 430056, China \\ ${ }^{\mathrm{c}}$ Beijing Urban Ecosystem Research Station, Research Center for Eco-Environmental Sciences, Chinese Academy of Sciences, Beijing 100085, China
}

\section{H I G H L I G H T S}

- $\Sigma \mathrm{Cl}_{1-3} \mathrm{DD} / \mathrm{Fs}$ accounted for $85 \%$ of $\Sigma \mathrm{Cl}_{1-8} \mathrm{DD} / \mathrm{Fs}$ in air samples.

- The mean concentration of $\Sigma \mathrm{Cl}_{1-3} \mathrm{DD} / \mathrm{Fs}$ was 5.4 times that of $\Sigma \mathrm{Cl}_{4-8} \mathrm{DD} / \mathrm{Fs}$ in the air

- $\Sigma \mathrm{Cl}_{1-3} \mathrm{DD} / \mathrm{Fs}$ occurred mainly in the gas phase, and $\Sigma \mathrm{Cl}_{4-8} \mathrm{DD} / \mathrm{Fs}$ mainly in particles.

- $\Sigma \mathrm{Cl}_{1-3} \mathrm{DFs}$ were the dominant form of $\Sigma \mathrm{Cl}_{1-3} \mathrm{DD} / \mathrm{Fs}$ in all particle size classes.

\section{A R T I C L E I N F O}

\section{Article history:}

Received 2 December 2015

Received in revised form 4 February 2016

Accepted 14 February 2016

Available online 15 March 2016

Handling Editor: Dr. Gang Yu

\section{Keywords:}

PCDD/Fs

Mono- to tri-chlorinated homologues

Atmosphere

Gas/particle partitioning

Particles

Distribution

\begin{abstract}
A B S T R A C T
There is very little information on the levels and particle size distributions of lower chlorinated dibenzo$p$-dioxins and dibenzofurans (mono- to tri-CDD/Fs, $\Sigma \mathrm{Cl}_{1-3} \mathrm{DD} / \mathrm{Fs}$ ) in the atmosphere, while a number of studies have examined tetra- to octa-chlorinated homologues $\left(\Sigma \mathrm{Cl}_{4-8} \mathrm{DD} / \mathrm{Fs}\right)$. In this study, we measured the concentration and particle size distribution of $\Sigma \mathrm{Cl}_{1-3} \mathrm{DD} / \mathrm{Fs}$ in ambient air in suburban Beijing and compared them with that of $\Sigma \mathrm{Cl}_{4-8} \mathrm{DD} / \mathrm{Fs}$ for the first time. The mean concentration of $\Sigma \mathrm{Cl}_{1-3} \mathrm{DD} / \mathrm{Fs}$ was $54.63 \mathrm{pg} \mathrm{m}^{-3}$, which is about 5.4 times that of $\Sigma \mathrm{Cl}_{4-8} \mathrm{DD} / \mathrm{Fs}$. The $\Sigma \mathrm{Cl}_{1-3} \mathrm{DD} / \mathrm{Fs}$ accounted for $85 \%$ of $\Sigma \mathrm{Cl}_{1}$ ${ }_{-8} \mathrm{DD} / \mathrm{Fs}$, and MoCDFs made up the largest proportion $(43 \%)$ of $\mathrm{PCDD} / \mathrm{F}$ homologues. The $\Sigma \mathrm{Cl}_{1-3} \mathrm{DD} / \mathrm{Fs}$ mainly occurred in the gas phase, while the $\Sigma \mathrm{Cl}_{4-8} \mathrm{DD} / \mathrm{Fs}$ mainly occurred in the particulate phase. The majority of $\Sigma \mathrm{Cl}_{1-3} \mathrm{DD} / \mathrm{Fs}(70 \%)$ occurred in $d_{\mathrm{ae}}>1.0 \mu \mathrm{m}$ particles, which is the reverse of the trend observed for $\Sigma \mathrm{Cl}_{4-8} \mathrm{DD} / \mathrm{Fs}$, of which $78 \%$ occurred in $d_{\mathrm{ae}}<1.0 \mu \mathrm{m}$ particles. The observed high concentrations of $\Sigma \mathrm{Cl}_{1-3} \mathrm{DD} / \mathrm{Fs}$ and different distribution patterns demonstrate that it is necessary to consider the lower chlorinated homologues to improve our understanding of the environmental behavior and health risk assessments of PCDD/Fs in the atmosphere.
\end{abstract}

๑) 2016 Elsevier Ltd. All rights reserved.

\section{Introduction}

Polychlorinated dibenzo-p-dioxins and dibenzofurans (PCDD/ Fs) are persistent organic pollutants that are byproducts of

\footnotetext{
* Corresponding author. State Key Laboratory of Environmental Chemistry and Ecotoxicology, Research Center for Eco-Environmental Sciences, Chinese Academy of Sciences, Beijing 100085, China. Tel.: +86 106284 9172; fax: +86 1062849172

E-mail address: zhengmh@rcees.ac.cn (M. Zheng).
}

industrial thermal and chemical processes (Liu et al., 2015a, 2015b), such as metal smelting (Ba et al., 2009; Nie et al., 2011), waste incineration (Ni et al., 2009; Tang et al., 2013), coking facility processes (Liu et al., 2009, 2013a), herbicide and pesticide production (Rappe et al., 1978; Holt et al., 2010), and chlorine bleaching in paper mills (Wang et al., 2012, 2014).

Previous studies have mainly focused on tetra- to octachlorinated homologues, especially the 17 2,3,7,8-PCDD/Fs (Li et al., 2008a; Zhu et al., 2008). Studies focusing on the lower chlorinated homologues (mono- to tri-) are scarce, probably 
because of the absence of assigned toxic equivalent factors for mono- to tri-chlorinated congeners. However, lower chlorinated congeners, such as 2-MoCDF and 3-MoCDF, have displayed embryotoxicity (Usami et al., 1993) and mutagenicity (Michi et al., 1988), respectively. Park et al. recently reported that workers at an incinerator facility and residents in the vicinity are exposed to high levels of $\Sigma \mathrm{Cl}_{1-3} \mathrm{DD} / \mathrm{Fs}$, and that $\Sigma \mathrm{Cl}_{1-3} \mathrm{DD} / \mathrm{Fs}$ concentrations made up $77 \%$ of the $\Sigma \mathrm{Cl}_{1-8} \mathrm{DD} / \mathrm{Fs}$ serum concentrations (Park et al., 2013). These results demonstrate that there is the potential for accumulation of mono- to tri-CDD/Fs in humans, and that the human health implications of exposure should be examined.

Ambient air is one of the most significant pathways of transport for PCDD/Fs (Tseng et al., 2014a,b; Chandra Suryani et al., 2015). Most previous studies on ambient air have focused on the levels and distribution patterns of tetra- to octa-CDD/Fs (Li et al., 2008b; Wang et al., 2010; Zhang et al., 2012, 2015). To our knowledge, there are no studies on the particle size distribution of lower chlorinated homologues and no comparisons of their distribution with that of higher chlorinated homologues in ambient air. In this study, we examined mono- to tri-CDD/F concentrations and distributions in different sized airborne particles, and compared them to those of tetra- to octa-chlorinated homologues in a Beijing suburban area. This evaluation is a preliminary step toward obtaining a more complete understanding of the particle size distribution of monoto octa-CDD/Fs.

\section{Materials and methods}

\subsection{Air sampling}

Our group has established a continuous and long term monitoring program at the Beijing urban ecosystem research station to collect atmospheric data. We collected the samples for this study from this site, and used previously collected data to ensure data stability and comparability (Zhang et al., 2015). Five air sample groups, including gas phase, and particle phase with aerodynamic diameters $\left(d_{a e} s\right)$ of four size classes: $>10 \mu \mathrm{m}, 2.5-10 \mu \mathrm{m}$, 1.0-2.5 $\mu \mathrm{m}$, and $<1.0 \mu \mathrm{m}$ were collected. Detailed information about the sampling sites and techniques are provided in our previous study (Zhang et al., 2015). Data on homologue and congener profiles, and particle size distribution of tetra- to octa-CDD/Fs in the atmosphere investigated in that study will be used to compare with data on mono- to tri-chlorinated homologues measured in this study.

\subsection{Pretreatment and instrumental analysis of mono- to tri-CDD/Fs}

Analysis of mono- to tri-CDD/Fs was performed as followed (Liu et al., 2013b). A ${ }^{13} \mathrm{C}_{12}$-labeled internal standard (EDF-4955; Cambridge Isotope Laboratories) consisted of six ${ }^{13} \mathrm{C}_{12}$-labeled congeners (2-MoCDD, 2-MoCDF, 2,3-DiCDD, 2,8-DiCDF, 2,3,7-TrCDD, $2,4,8-\operatorname{Tr} \mathrm{CDF}$ ) was added prior to extraction, then the samples were extracted by an accelerated solvent extraction (ASE, Thermo Fisher Scientific, Waltham, MA, USA) with a mixture of dichloromethane and hexane $(1: 1 \mathrm{v} / \mathrm{v})$.

The details about the sample clean-up were previously described (Liu et al., 2013b). A multilayer silica gel column was firstly used to purify the extract and the target compounds on the column were eluted with $100 \mathrm{~mL}$ of hexane. Then, the extract was evaporated and further cleanup on an $8 \mathrm{~g}$ basic alumina column, and eluted with $80 \mathrm{~mL}$ of $2 \%$ dichloromethane in hexane, followed by $150 \mathrm{~mL}$ of $12 \%$ dichloromethane in hexane. Mono- to tri-CDD/F congeners were contained in the latter fraction. The extract was concentrated to about $40 \mu \mathrm{L}$ by rotatory evaporation and gentle nitrogen flow prior to instrumental analysis.
The mono- to tri-CDD/Fs were analyzed using an Agilent 6890 gas chromatograph (Agilent Technologies, Santa Clara, CA, USA) equipped with a DB-5 MS fused silica column (60 m long, $0.25 \mathrm{~mm}$ inner diameter, $0.25 \mu \mathrm{m}$ film thickness, Agilent Technologies) that was coupled to an Autospec Ultima high resolution mass spectrometer (Waters, Milford, MA, USA) with an electron impact (EI) ion source (Liu et al., 2013b). The mass spectrometer was operated at the resolution of at least 10,000 and was operated in selected ion monitoring mode. Five pairs of field blanks and laboratory blanks were analyzed, and no differences in $\mathrm{PCDD} / \mathrm{F}$ concentrations were observed between these groups. Recoveries of the ${ }^{13} \mathrm{C}_{12}$-labeled mono- to tri-CDD/F congeners were between $47 \%$ and $89 \%$.

\section{Results and discussion}

The mean concentration of $\Sigma \mathrm{Cl}_{1-3} \mathrm{DD} / \mathrm{Fs}$ was $54.63 \mathrm{pg} \mathrm{m}^{-3}$, which was about 5.4 times that of $\Sigma \mathrm{Cl}_{4-8} \mathrm{DD} / \mathrm{Fs} . \quad \Sigma \mathrm{Cl}_{1-3} \mathrm{DD} / \mathrm{Fs}$ accounted for $85 \%$ of $\Sigma \mathrm{Cl}_{1-8} \mathrm{DD} / \mathrm{Fs}$. MoCDFs were the dominant homologue of PCDD/Fs, accounting for $43 \%$ of $\Sigma \mathrm{Cl}_{1-8} \mathrm{DD} / \mathrm{Fs}$. The dominant contributor to MoCDFs was 3-MoCDF (46\%) of MoCDFs, followed by $4-\operatorname{MoCDF}(30 \%)$ (Table 1 ). The concentrations of 2,8DiCDF and 2,4,8-TrCDF were lower than those of 3-MoCDF. Our previous research demonstrated that $1,2,3,4,6,7,8-\mathrm{HpCDF}$ and OCDF were the most abundant congeners of $172,3,7,8$-PCDD/Fs, accounting for only $4.4 \%$ and $4.2 \%$ of $3-\mathrm{MoCDF}$, respectively (Zhang et al., 2015). The concentrations of $\Sigma \mathrm{Cl}_{1-3} \mathrm{DD} / \mathrm{Fs}$ in these samples are higher than those of $\Sigma \mathrm{Cl}_{4-8} \mathrm{DD} / \mathrm{Fs}$, and the associated environmental and health risks of $\Sigma \mathrm{Cl}_{1-3} \mathrm{DD} / \mathrm{Fs}$ in the atmosphere should not be ignored.

The gas/particle partitioning behaviors of different PCDD/F homologues, especially between $\Sigma \mathrm{Cl}_{1-3} \mathrm{DD} / \mathrm{Fs}$ and $\Sigma \mathrm{Cl}_{4-8} \mathrm{DD} / \mathrm{Fs}$, were obviously different (Fig. 1). $\Sigma \mathrm{Cl}_{1-3} \mathrm{DD} / \mathrm{Fs}$ were abundant in the gas phase, accounting for $95 \%$ of $\Sigma \mathrm{Cl}_{1-8} \mathrm{DD} / \mathrm{Fs} ; \Sigma \mathrm{Cl}_{1-3} \mathrm{DFs}$ were particularly prevalent, accounting for $>96 \%$ of $\Sigma \mathrm{Cl}_{1-8}$ DFs. $\Sigma \mathrm{Cl}_{1-3} \mathrm{DD} / \mathrm{Fs}$ were the main $\mathrm{PCDD} / \mathrm{F}$ homologues in the gas phase, while $\Sigma \mathrm{Cl}_{4-8} \mathrm{DD} / \mathrm{Fs}$ were the dominant homologues in the particulate phase, accounting for $73 \%$ of $\Sigma \mathrm{Cl}_{1-8} \mathrm{DD} / \mathrm{Fs}$ (Zhang et al., 2015).

The partition of particle matter with different sizes and mono-

Table 1

Concentration profiles of mono- to tri-CDD/F homologues and congeners in the samples, expressed as mass concentrations $\left(\mathrm{pg} \mathrm{m}^{-3}\right)$.

\begin{tabular}{|c|c|c|c|c|c|c|c|c|}
\hline & \multirow[t]{2}{*}{ S1 } & \multirow[t]{2}{*}{$\mathrm{S} 2$} & \multirow[t]{2}{*}{ S3 } & \multirow[t]{2}{*}{ S4 } & \multirow[t]{2}{*}{ S5 } & \multicolumn{3}{|l|}{ Mean } \\
\hline & & & & & & Gas & Particles & Total \\
\hline 1-MoCDF & 5.03 & 3.83 & 5.15 & 5.15 & 1.24 & 3.91 & 0.17 & 4.08 \\
\hline 2-MoCDF & 1.66 & 1.26 & 3.69 & 2.88 & 2.39 & 2.26 & 0.12 & 2.38 \\
\hline 3-MoCDF & 15.57 & 11.87 & 17.71 & 13.16 & 5.08 & 12.36 & 0.32 & 12.68 \\
\hline 4-MoCDF & 11.53 & 8.79 & 11.53 & 8.97 & 2.42 & 8.43 & 0.22 & 8.65 \\
\hline 2,8-DiCDF & 0.86 & 0.65 & 0.81 & 0.98 & 0.68 & 0.77 & 0.03 & 0.79 \\
\hline $2,4,8-\operatorname{TrCDF}$ & 2.61 & 1.98 & 2.81 & 6.96 & 4.15 & 3.54 & 0.16 & 3.70 \\
\hline 1-MoCDD & 0.74 & 0.56 & 0.82 & 1.27 & 0.24 & 0.69 & 0.04 & 0.73 \\
\hline 2-MoCDD & 0.07 & 0.05 & 0.06 & 0.04 & 0.02 & 0.01 & 0.04 & 0.05 \\
\hline 2,3-DiCDD & 0.12 & 0.09 & 0.13 & 0.09 & 0.04 & 0.05 & 0.04 & 0.09 \\
\hline 2,3,7-TrCDD & 0.71 & 0.53 & 0.33 & 0.30 & 0.10 & 0.34 & 0.06 & 0.39 \\
\hline MoCDF & 33.79 & 25.75 & 38.08 & 30.17 & 11.13 & 26.96 & 0.83 & 27.78 \\
\hline DiCDF & 9.04 & 11.97 & 16.15 & 15.63 & 8.29 & 11.78 & 0.53 & 12.31 \\
\hline TrCDF & 7.92 & 11.13 & 12.23 & 18.66 & 11.26 & 11.41 & 1.02 & 12.43 \\
\hline MoCDD & 0.81 & 0.61 & 0.88 & 1.31 & 0.26 & 0.7 & 0.08 & 0.78 \\
\hline DiCDD & 0.43 & 1.2 & 1.1 & 0.95 & 0.45 & 0.37 & 0.56 & 0.93 \\
\hline $\operatorname{TrCDD}$ & 0.46 & 0.94 & 0.94 & 0.86 & 0.76 & 0.59 & 0.25 & 0.85 \\
\hline$\Sigma \mathrm{Cl}_{1-3} \mathrm{DD} / \mathrm{Fs}$ & 52.45 & 51.6 & 69.38 & 67.57 & 32.16 & 51.81 & 2.82 & 54.63 \\
\hline$\Sigma \mathrm{Cl}_{4-8} \mathrm{DD} / \mathrm{Fs}^{\mathrm{a}}$ & 10.16 & 23.17 & 6.59 & 7.13 & 3.77 & 2.7 & 7.47 & 10.17 \\
\hline$\Sigma \mathrm{Cl}_{1-8} \mathrm{DD} / \mathrm{Fs}^{\mathrm{a}}$ & 62.62 & 74.78 & 75.97 & 74.69 & 35.94 & 54.51 & 10.29 & 64.80 \\
\hline
\end{tabular}

Abbreviations: mono $=\mathrm{Mo}$; $\mathrm{di}=\mathrm{Di}$; tri $=\mathrm{Tr}$; tetra $=\mathrm{Te}$; penta $=\mathrm{Pe}$; hexa $=\mathrm{Hx}$ hepta $=\mathrm{Hp}$; octa $=0 . \Sigma \mathrm{Cl}_{1-3} \mathrm{DD} / \mathrm{Fs}$ : the sum of mono- to tri-CDD/Fs. $\Sigma \mathrm{Cl}_{4-8} \mathrm{DD} / \mathrm{Fs}$ the sum of tetra- to octa-CDD/Fs; $\Sigma \mathrm{Cl}_{1-8} \mathrm{DD} / \mathrm{Fs}$ : the sum of mono- to octa-CDD/Fs.

a the related data from the our previous study (Zhang et al., 2015). 


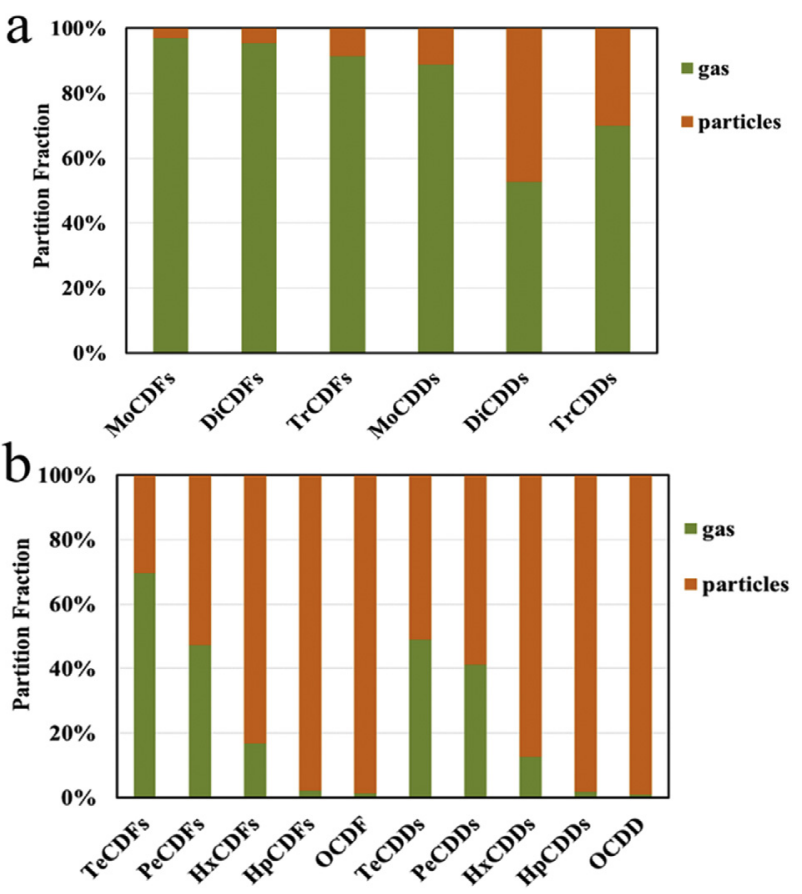

Fig. 1. PCDD/F homologue distributions in the gas and particle phases: (a) Mono- to tri-CDD/Fs; (b) Tetra- to Octa-CDD/Fs (Zhang et al., 2015). to tri-CDD/Fs in different sizes in the air were presented in Fig. 2. The proportion of $\Sigma \mathrm{Cl}_{1-3} \mathrm{DD} / \mathrm{Fs}$ occurring in the $d_{a e}<1.0 \mu \mathrm{m}$ particle size fraction was slightly higher than in other particle size fractions (Fig. 2(a)). In $d_{a e}>1.0 \mu \mathrm{m}$ particles, the proportion of $\Sigma \mathrm{Cl}_{1-3} \mathrm{DD} / \mathrm{Fs}$ in three size classes $(>10 \mu \mathrm{m}, 2.5-10 \mu \mathrm{m}$, and $1.0-2.5 \mu \mathrm{m})$ were almost the same. $\Sigma \mathrm{Cl}_{1-3} \mathrm{DD} / \mathrm{Fs}$ primarily occurred in the $d_{a e}>1.0 \mu \mathrm{m}$ fraction. The sum of the proportions (\%) of $\Sigma \mathrm{Cl}_{1-3} \mathrm{DD} / \mathrm{Fs}$ in $d_{a e}>1.0 \mu \mathrm{m}$ particles were around $70 \%$, higher than that in $d_{a e}<1.0 \mu \mathrm{m}$ particles (30\%). We also observed that $78 \%$ of $\Sigma \mathrm{Cl}_{4-8} \mathrm{DD} / \mathrm{Fs}$ occurred in the fine particle fractions $\left(d_{a e}<1.0 \mu \mathrm{m}\right)$, and proportions increased as particle size decreased (Fig. S1(a)). Normalized histograms representing $d C / d \log D p$ versus $D p$ have been intensively used for investigating PCDD/F distribution in different air particle size classes (Chao et al., 2003; Chrysikou and Samara, 2009). $d C$ is the concentration of PCDD/Fs in each size fraction, and $D p$ is the aerodynamic diameter. The distribution of $\Sigma \mathrm{Cl}_{1-3} \mathrm{DD} / \mathrm{Fs}$ (Fig. 2(b)) was also clearly different from the distribution of $\Sigma \mathrm{Cl}_{4-8} \mathrm{DD} / \mathrm{Fs}$ (Fig. S1(b)).

We observed that $\Sigma \mathrm{Cl}_{1-3} \mathrm{DFs}$ occurred in higher proportions than $\Sigma \mathrm{Cl}_{1-3} \mathrm{DDs}$ in all size classes of particles. $\Sigma \mathrm{Cl}_{1-3} \mathrm{DFs}$ accounted for more than $70 \%$ of the $\Sigma \mathrm{Cl}_{1-3} \mathrm{DD} / \mathrm{Fs}$ in the particle phase (Fig. 3(a)). In the $\Sigma \mathrm{Cl}_{1-3} \mathrm{DF}$ homologues, higher chlorinated furans occurred in higher fractions in the fine particle size fraction. 3MoCDF and 4-MoCDF were the most prevalent congeners of MoCDFs. MoCDFs have a greater tendency to partition in the gas phase relative to higher chlorinated $\mathrm{DD} / \mathrm{Fs}$. To the best of our knowledge, there have been no previous reports of MoCDF congeners in airborne particles of different sizes. Therefore, it is important to investigate the distribution of MoCDF congeners in
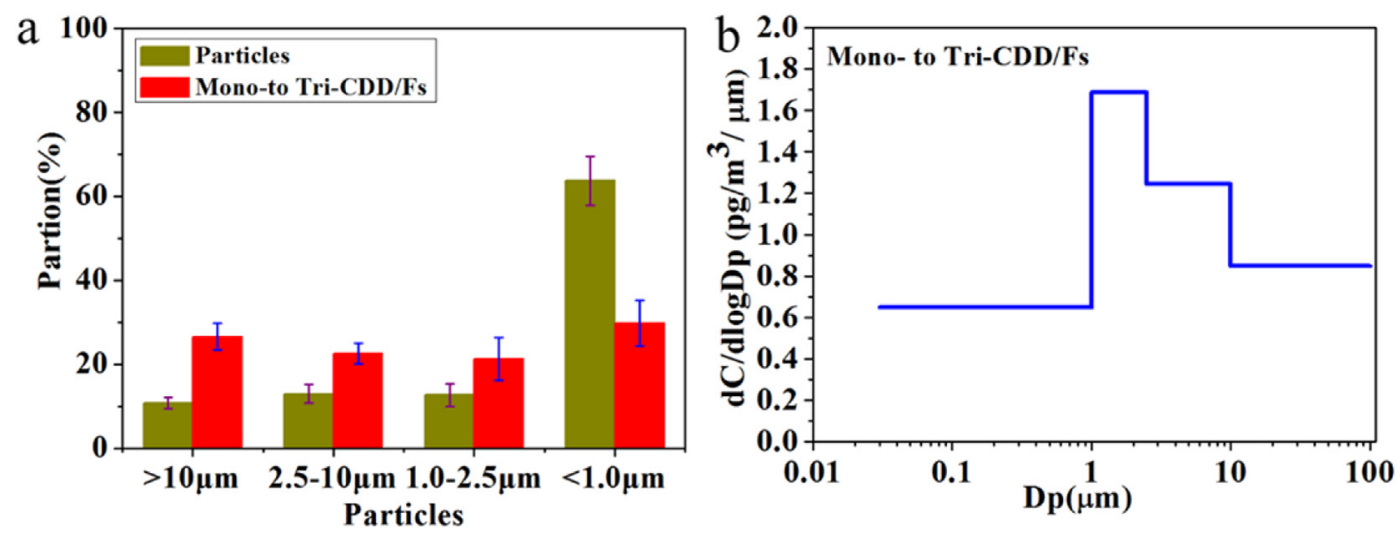

Fig. 2. Proportions of mono- to tri-CDD/Fs different size classes of atmospheric particles.
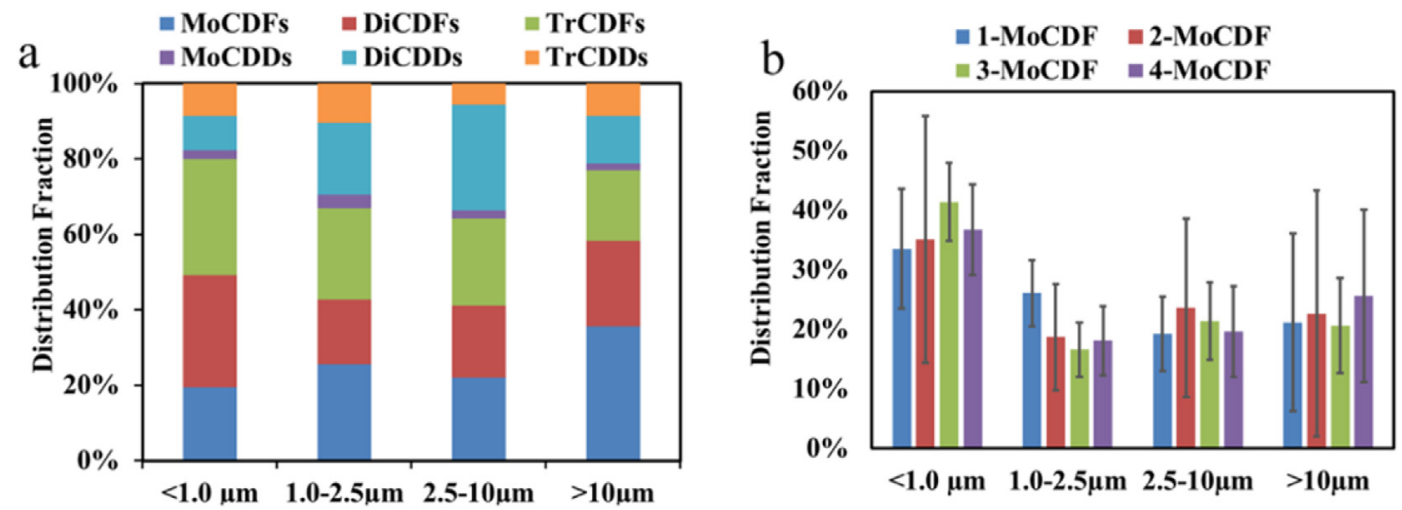

Fig. 3. Mono- to tri-chlorinated homologues and congeners in different size classes of atmospheric particles. 
the air to for better understanding of their environmental behavior and impacts on human health. The distribution of MoCDF congeners in different size classes of airborne particles is presented in the Fig. 3(b). The proportions of four MoCDF congeners in the $d_{a e}<1.0 \mu \mathrm{m}$ size class (around 35\%) are slightly higher than those occurring in the $1.0-2.5 \mu \mathrm{m}, 2.5-10 \mu \mathrm{m}$, and $>10 \mu \mathrm{m}$ size classes. The distribution of the four MoCDF congeners in the $1.0-2.5 \mu \mathrm{m}$, 2.5-10 $\mu \mathrm{m}$, and $>10 \mu \mathrm{m}$ size classes were almost the same (about $22 \%$ ). This was different from the particle size distribution of higher chlorinated homologues (such as OCDF), for which the distribution in the $d_{a e}<1.0 \mu \mathrm{m}$ particles was about $80 \%$, and concentrations in particles of each size fraction decreased as the particle size increased (Fig. S2). These results may be helpful in gaining a better understanding of the environmental behavior and potential health risk of MoCDFs, which are a significant component of PCDD/Fs in the atmosphere.

\section{Conclusions}

We observed higher concentrations $\Sigma \mathrm{Cl}_{1-3} \mathrm{DD} / \mathrm{Fs}$ than $\Sigma \mathrm{Cl}_{4-8} \mathrm{DD} / \mathrm{Fs}$ (by about 5.4 times) in atmospheric samples, indicating that residents in the investigated areas may be exposed to higher levels of lower chlorinated DD/Fs. $\Sigma \mathrm{Cl}_{1-3} \mathrm{DD} / \mathrm{Fs}$ mainly occurred in the gas phase, while $\Sigma \mathrm{Cl}_{4-8} \mathrm{DD} / \mathrm{Fs}$ were dominant in the particulate phase (Zhang et al., 2015). We also observed that $\Sigma \mathrm{Cl}_{1-3} \mathrm{DD} / \mathrm{Fs}$ occurred in higher proportions in $d_{\mathrm{ae}}>1.0 \mu \mathrm{m}$ particles; this is the opposite of the distribution trend observed for $\Sigma \mathrm{Cl}_{4-8} \mathrm{DD} / \mathrm{Fs}$, of which about $80 \%$ occur in $d_{\mathrm{ae}}<1.0 \mu \mathrm{m}$ particles.

\section{Acknowledgments}

This work was supported by the National 973 Program (2015CB453100), Strategic Priority Research Program of the Chinese Academy of Sciences (XDB14020000), and National Natural Science Foundation of China (21361140359, 91543108, 21577148).

\section{Appendix A. Supplementary data}

Supplementary data related to this article can be found at http:// dx.doi.org/10.1016/j.chemosphere.2016.02.059.

\section{References}

Ba, T., Zheng, M., Zhang, B., Liu, W., Su, G., Xiao, K., 2009. Estimation and characterization of PCDD/Fs and dioxin-like PCB emission from secondary zinc and lead metallurgies in China. J. Environ. Monit. 11, 867-872.

Chandra Suryani, R., Lee, W.-J., Endah Mutiara, M., Mwangi, J.K., Wang, L.-C., Lin, N.H., Chang-Chien, G.-P., 2015. Atmospheric deposition of polychlorinated dibenzo-p-dioxins and dibenzofurans at coastal and high mountain areas in Taiwan. Aerosol Air Qual. Res. 15, 1390-1411.

Chao, M.-R., Hu, C.-W., Ma, H.-W., Chang-Chien, G.-P., Lee, W.-J., Chang, L.W., Wu, K.Y., 2003. Size distribution of particle-bound polychlorinated dibenzo-p-dioxins and dibenzofurans in the ambient air of a municipal incinerator. Atmos. Environ. 37, 4945-4954.

Chrysikou, L.P., Samara, C.A., 2009. Seasonal variation of the size distribution of urban particulate matter and associated organic pollutants in the ambient air. Atmos. Environ. 43, 4557-4569.

Holt, E., Weber, R., Stevenson, G., Gaus, C., 2010. Polychlorinated dibenzo-p-dioxins and dibenzofurans (PCDD/Fs) impurities in pesticides: a neglected source of contemporary relevance. Environ. Sci. Technol. 44, 5409-5415.

Li, H., Feng, J., Sheng, G., Lü, S., Fu, J., Peng, P.a., Man, R., 2008a. The PCDD/F and $\mathrm{PBDD} / \mathrm{F}$ pollution in the ambient atmosphere of Shanghai, China. Chemosphere 70, 576-583.

Li, Y., Jiang, G., Wang, Y., Cai, Z., Zhang, Q., 2008b. Concentrations, profiles and gas-particle partitioning of polychlorinated dibenzo-p-dioxins and $\mathrm{di}$ benzofurans in the ambient air of Beijing, China. Atmos. Environ. 42, 2037-2047.

Liu, G., Zheng, M., Liu, W., Wang, C., Zhang, B., Gao, L., Su, G., Xiao, K., Lv, P., 2009 Atmospheric emission of PCDD/Fs, PCBs, hexachlorobenzene, and pentachlorobenzene from the coking industry. Environ. Sci. Technol. 43, 9196-9201.

Liu, G.R., Jiang, X.X., Wang, M., Dong, S.J., Zheng, M.H., 2015a. Comparison of PCDD/F levels and profiles in fly ash samples from multiple industrial thermal sources. Chemosphere 133, 68-74.

Liu, G.R., Liu, W.B., Cai, Z.W., Zheng, M.H., 2013a. Concentrations, profiles, and emission factors of unintentionally produced persistent organic pollutants in fly ash from coking processes. J. Hazard. Mater. 261, 421-426.

Liu, G.R., Zhan, J.Y., Zheng, M.H., Li, L., Li, C.P., Jiang, X.X., Wang, M., Zhao, Y.Y., Jin, R., 2015b. Field pilot study on emissions, formations and distributions of PCDD/Fs from cement kiln co-processing fly ash from municipal solid waste incinerations. J. Hazard. Mater. 299, 471-478.

Liu, W., Tian, Z., Li, H., Xie, H., Xiao, K., Li, C., Tang, C., Zheng, M., 2013b. Mono- to octa-chlorinated PCDD/Fs in stack gas from typical waste incinerators and their implications on emission. Environ. Sci. Technol. 47, 9774-9780.

Michi, M., Mitsuru, A., Yukiko, O., 1988. Mutagenicity of monochlorodibenzofurans detected in the environment. Toxicol. Lett. 40, 21-28.

Ni, Y., Zhang, H., Fan, S., Zhang, X., Zhang, Q., Chen, J., 2009. Emissions of PCDD/Fs from municipal solid waste incinerators in China. Chemosphere 75, 1153-1158.

Nie, Z., Zheng, M., Liu, W., Zhang, B., Liu, G., Su, G., Lv, P., Xiao, K., 2011. Estimation and characterization of PCDD/Fs, dl-PCBs, PCNs, $\mathrm{HxCBz}$ and $\mathrm{PeCBz}$ emissions from magnesium metallurgy facilities in China. Chemosphere 85, 1707-1712.

Park, H., Kim, J., Chang, Y.-S., 2013. Prevalence of low chlorinated dibenzo-p-dioxin/ dibenzofurans in human serum. Chemosphere 90, 1658-1663.

Rappe, C., Buser, H.R., Bosshardt, H.-P., 1978. Identification and quantification of polychlorinated dibenzo-p-dioxins (PCDDs) and dibenzofurans (PCDFs) in 2, 4, 5-T-ester formulations and herbicide orange. Chemosphere 7, 431-438.

Tang, Z., Huang, Q., Yang, Y., 2013. PCDD/Fs in fly ash from waste incineration in china: a need for effective risk management. Environ. Sci. Technol. 47, 5520-5521.

Tseng, Y.-J., Mi, H.-H., Hsieh, L.-T., Liao, W.-T., Chang-Chien, G.-P., 2014a. Atmospheric deposition modeling of polychlorinated dibenzo-p-dioxins, dibenzofurans and polychlorinated biphenyls in the ambient air of Southern Taiwan. Part I. Dry depositions. Aerosol Air Qual. Res. 14, 1950-1965.

Tseng, Y.-I., Mi, H.-H., Hsieh, L.-T., Liao, W.-T., Chang-Chien, G.-P., 2014b. Atmospheric deposition modeling of polychlorinated dibenzo-p-dioxins, dibenzofurans and polychlorinated biphenyls in the ambient air of Southern Taiwan. Part II. Wet depositions and total deposition fluxes. Aerosol Air Qual. Res. 14, 1966-1985.

Usami, M., Sakemi, K., Tabata, H., Kawashima, K., Takanaka, A., 1993. Developmenta toxicity of 2-chlorodibenzofuran in cultured post-implantation rat embryos. Toxicol. Vitro 7, 259-264.

Wang, M.-S., Chen, S.-J., Huang, K.-L., Lai, Y.-C., Chang-Chien, G.-P., Tsai, J.-H., Lin, W.Y., Chang, K.-C., Lee, J.-T., 2010. Determination of levels of persistent organic pollutants (PCDD/Fs, PBDD/Fs, PBDEs, PCBs, and PBBs) in atmosphere near a municipal solid waste incinerator. Chemosphere 80, 1220-1226.

Wang, X., Ni, Y., Zhang, H., Zhang, X., Chen, J., 2012. Formation and emission of PCDD/Fs in Chinese non-wood pulp and paper mills. Environ. Sci. Technol. 46 12234-12240.

Wang, X., Zhang, H., Ni, Y., Du, Q., Zhang, X., Chen, J., 2014. Kinetics of PCDD/Fs formation from non-wood pulp bleaching with chlorine. Environ. Sci. Technol. 48, 4361-4367.

Zhang, T., Huang, Y.R., Chen, S.J., Liu, A.M., Xu, P.J., Li, N., Qi, L., Ren, Y., Zhou, Z.G. Mai, B.X., 2012. PCDD/Fs, PBDD/Fs, and PBDEs in the air of an e-waste recycling area (Taizhou) in China: current levels, composition profiles, and potential cancer risks. J. Environ. Monit. 14, 3156-3163.

Zhang, X., Zhu, Q.-Q., Dong, S.-J., Zhang, H.-X., Wang, X.-K., Wang, M., Gao, L.-R., Zheng, M.-H., 2015. Particle size distributions of PCDD/Fs and PBDD/Fs in ambient air in a suburban area in Beijing, China. Aerosol Air Qual. Res. 15, 1933-1943.

Zhu, J., Hirai, Y., Yu, G., Sakai, S.-i., 2008. Levels of polychlorinated dibenzo-p-dioxins and dibenzofurans in China and chemometric analysis of potential emission sources. Chemosphere 70, 703-711. 